\title{
What are Children's Breakfast Habits and How is Breakfast Meal Perceived by them? A Study Carried out in Pavia, Northern Italy
}

\section{Turconi $\mathrm{G}^{*}$, Moro $\mathrm{S}^{2}$, Testa $\mathrm{L}^{1}$, Rossi $\mathrm{M}^{2}$, Porzio $\mathrm{E}^{2}$, Roggi $\mathrm{C}^{1}$, Valenti $\mathrm{A}^{3}$ and Maccarini $\mathrm{L}^{2}$}

${ }^{1}$ Department of Public Health, Experimental and Forensic Medicine, Unit of Human Nutrition and Dietetics ${ }^{2}$ Department of Public Health, Experimental and Forensic Medicine, Unit of Hygiene and Preventive MedicineFaculty of Medicine, University of Pavia, Pavia, Italy ${ }^{3}$ Psychology Medical Centre Mara Selvini, Pavia, Italy

${ }^{*}$ Corresponding author: Turconi G, Department of Public Health, Experimental and Forensic Medicine Unit of Human Nutrition and Dietetics, Faculty of Medicine - University of Pavia - Italy- Via Bassi, 21 - I 27100 Pavia, Italy, Fax: 00390382 987191, Tel: 00390382 987544,E-mail: gturconi@unipv.it

Citation: Turconi G, Moro S, Testa L, Rossi M, Porzio E, et al. (2015) What are Children's Breakfast Habits and How is Breakfast Meal Perceived by them? A Study Carried out in Pavia, Northern Italy. J Nutr Health Sci 2(2): 201. doi: 10.15744/2393-9060.2.201

Received Date: January 20, 2015 Accepted Date: May 18, 2015 Published Date: May 20, 2015

\begin{abstract}
Regular breakfast eating has been associated with a better health status and wellbeing at any age and promotes an overall dietary quality and nutritional adequacy. It has been shown by an increasing number of papers in the literature that children consuming breakfast on a regular basis tend to have better nutritional profiles than their breakfast skipping counterparts. The aim of this study was to investigate breakfast habits among primary school pupils and to evaluate how they perceive this meal.

A cross sectional study has been conducted in 2012 in all public primary schools in Pavia, Northern Italy. All pupils of both sexes attending the second year (aged $7.7 \pm 0.4$ years; range 7-8.5) were invited to complete a questionnaire, as well as a breakfast food diary and to draw a picture of their breakfast meal.

The results were encouraging since $84.3 \%$ of the pupils ate breakfast regularly every day, $7.7 \%$ almost daily while only $8.0 \%$ did not consume it regularly or skipped it. Seventy three point three percent of the pupils consumed an adequate breakfast with milk or yogurt and cereals products; many of them ate also a fruit or drank a fruit juice. Only $10.3 \%$ consumed an unsatisfactory and incomplete breakfast. Qualitative analysis of the breakfast pictures showed that most of the children (92.0\%) liked to consume breakfast every day with their family and considered it a very pleasant occasion.

In conclusion, our results showed positive and encouraging data regarding the consumption of breakfast by the children in Pavia. Although the results were satisfactory, efforts should be aimed at reinforcing children's positive habits and encouraging these throughout entire life. Parents of pupils skipping breakfast should encourage their children to assume this meal to improve their dietary quality as well as nutrient profile.

Keywords: Breakfast meal; Breakfast food diary; Breakfast picture
\end{abstract}

\section{Introduction}

Regular breakfast eating has been associated with a better health status and wellbeing at any age; this has been shown by an increasing number of papers in the literature regarding this topic in various worldwide countries with dietary habits very different one to each other's.

Breakfast eating is important to overall dietary quality and nutritional adequacy especially among school children [1,2] and children who report consuming breakfast on a regular basis tend to have better nutritional profiles than their breakfast skipping counterparts [2-4]. In addition, children who do not regularly eat breakfast are less likely to regularly eat lunch and/or dinner and are significantly more likely to consume snack foods, mostly between meals [5,6]. Consuming a complete and well-balanced breakfast avoids hunger feelings in the morning [2] which can lead to nibbling snack foods, particularly those high in sugar and fat [7].

Breakfast skipping can interfere with cognition and learning among children [2,3] and has been associated with mental distress and impaired academic performance among adolescents $[2,8]$. On the other hand, breakfast eating may improve cognitive function related to memory, test grades, school attendance and academic performance [2,3,9-13]. In addition, regular breakfast consumption among children and adolescents has been positively associated with intake of most vitamins and minerals [5,14-16], while those missing breakfast were more likely to be frequent consumers of unhealthy snack foods. Indeed, percentage of total daily energy intake was higher from fats and lower from carbohydrates for adolescents skipping breakfast $[5,14]$. 
Several studies have identified a possible role for breakfast consumption in maintaining normal weight status in children and adolescents, which may have important public health implications [3]. Indeed, many cross-sectional studies have well documented a relationship between skipping breakfast and higher body mass index (BMI) [5,6,15,17-30], whereas breakfast eating has been shown to be associated with a lower BMI [2,31-33]. It is well known that food behaviors and food choices established in childhood or adolescence may significantly track into adulthood $[2,34]$.

The aim of this study was to investigate breakfast habits among primary school pupils in Pavia, Northern Italy, and to evaluate how they perceive this meal.

\section{Methods}

Pupils of both sexes attending the second year of all the primary schools $(n=13)$ in Pavia, Northern Italy, were recruited ( $n=470)$ in 2012. Four hundred and forty eight healthy subjects (95.3\% of the entire sample) participated in the study, 52.5\% males and $47.5 \%$ females, among whom 71 were from non-European countries but recently immigrated to Italy. Twenty two children, 16 Italians and 6 foreigners, refused to participate because their parents were not interested in the project. The mean age of the sample is $7.7 \pm 0.4$ years (range $7-8.5$ ).

This survey was carried out as part of a wider nutritional surveillance project conducted with the cooperation of the Education Department of Pavia City Hall, that also included investigation into the meals consumed in school canteens [35], assessment of children's anthropometric measurements [36], investigation of children's and families' dietary habits, children's physical activity level as well as the families' educational level and socioeconomic status and parents' BMI. We decided to select only the second year primary school pupils, as we intend to follow up the children until the last year of primary school after a nutritional education intervention will be provided by the school teachers.

The whole study was conducted with the cooperation of both the school teachers and the Education Department of Pavia City Hall. Before beginning the study, many meetings were organized together with teachers to explain the aim of the research and to request their participation.

Children's parents were informed of the purpose of the research by a letter, that was sent together with a consent form through which written informed consent was obtained from them.

This study was conducted according to the guidelines laid down in the Declaration of Helsinki and all procedures involving human subjects were approved by the Ethics Committees of Pavia University Medical School.

\section{Children's breakfast habits}

Children's breakfast habits were investigated by the use of a target questionnaire previously developed that was self-administered during school time. The questionnaire consisted of three sections:

Section one (questionnaire): It included ten breakfast meal-related questions with pre coded answers, reported in Table 1.

\begin{tabular}{|l|c|l|c|}
\hline What time do you get up in the morning? & $\%$ & With do you have breakfast whom? & $\%$ \\
\hline Before 7 o'clock & 35.9 & Alone & 27.9 \\
\hline After 7 o'clock & 64.1 & With my family & 72.1 \\
\hline Do you have breakfast in the morning? & & How long do you take to have breakfast? & \\
\hline Every day & 84.3 & 15 minutes & 79.7 \\
\hline Often & 7.7 & 30 minutes & 20.3 \\
\hline Sometimes & 7.3 & & \\
\hline Never & 0.7 & & \\
\hline Do you have breakfast with pleasure? & & What do you do while having breakfast? & \\
\hline Yes & 94.9 & I eat silently & 30.8 \\
\hline No & 5.1 & I talk with my family members & 32.2 \\
\hline & & I play & 1.4 \\
\hline & & I read & 0.2 \\
\hline & & I read again my lesson & 0.9 \\
\hline & & I watch the television & 33.1 \\
\hline & & I listen to the music & 0.7 \\
\hline & I do not have breakfast & 0.7 \\
\hline
\end{tabular}




\begin{tabular}{|l|c|l|c|}
\hline $\begin{array}{l}\text { If sometimes you do not have breakfast, what is } \\
\text { the reason? }\end{array}$ & What do you like most of breakfast? & \\
\hline I am sleepy & 14.4 & What I eat and drink & 39.1 \\
\hline I have no time & 49.8 & Foods smelling & 5.6 \\
\hline I am not hungry & 29.8 & Foods flavor & 23.2 \\
\hline Breakfast is not prepared & 4.5 & To stay with my family members & 26.7 \\
\hline I do not like what mammy prepares & 1.5 & Nothing & 5.4 \\
\hline Where do you have breakfast? & & When do you brush your teeth? & \\
\hline At home, seated at the table & 91.7 & Before breakfast consumption & 5.1 \\
\hline At home, standing up & 0.9 & After breakfast consumption & 82.9 \\
\hline At home, in the bed & 3.8 & Before and after breakfast consumption & 8.9 \\
\hline At a bar & 1.9 & & 3.1 \\
\hline While I am going to school & 1.7 & I do not brush my teeth & \\
\hline
\end{tabular}

Section two (qualitative breakfast food diary): It included a food diary picture related to breakfast meal (Figure1), that the children had to complete pointing out which foods and beverages they consumed at breakfast time.

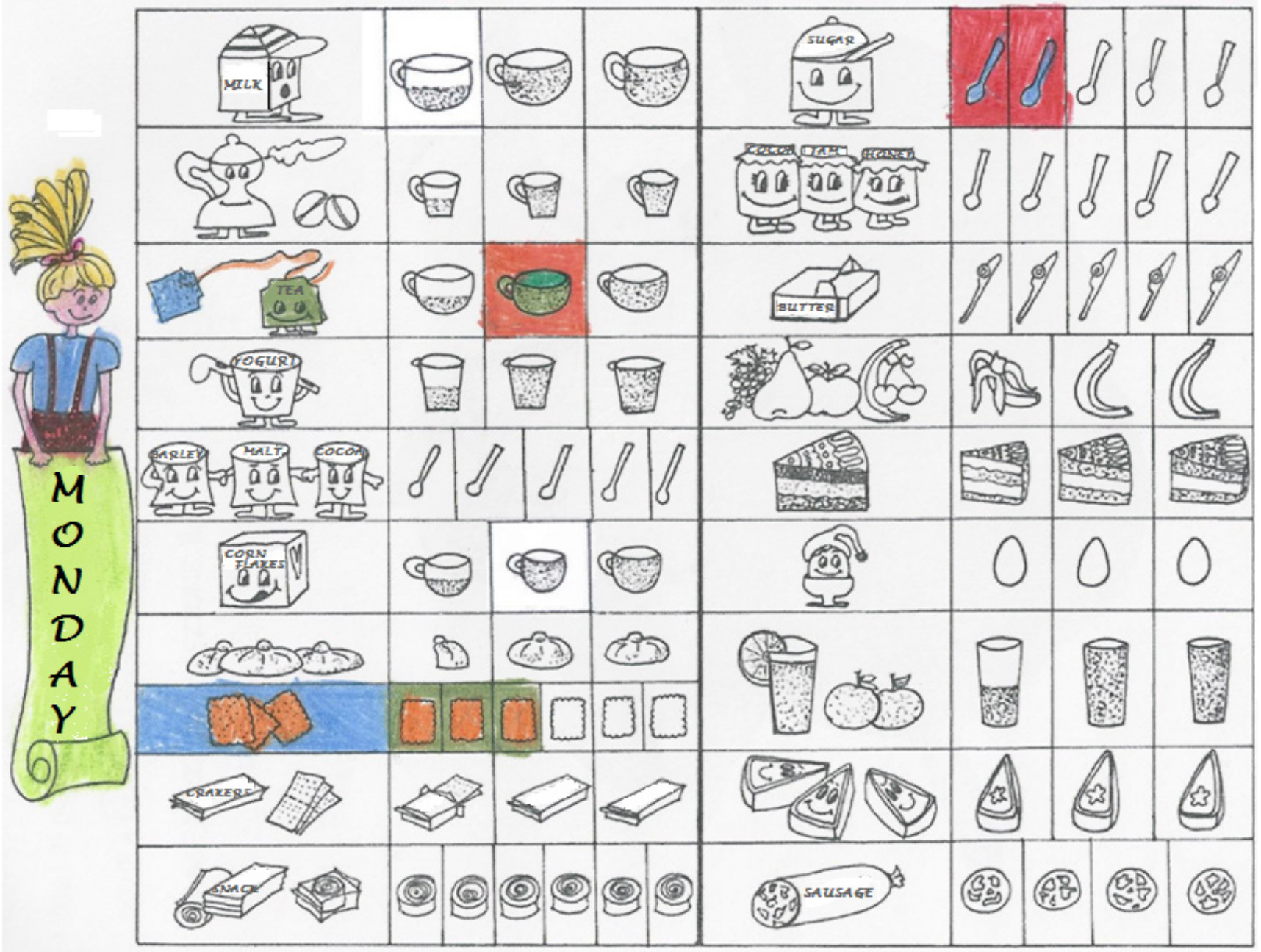

Figure 1: Breakfast diary

Section three (breakfast picture): It included a white paper on which children were invited to draw a picture of their own breakfast.

The items of section one were developed by a team of three dieticians. The questionnaire was previously piloted on a sample of 52 children and revised accordingly, but validity and reliability were not formally tested.

It took thirty minutes to complete sections one and two and about one hour to draw the breakfast picture. 


\section{Data analysis}

All statistical analyses were performed using SPSS statistical software package for Windows Version 18.0 (SPSS Inc., Chicago, IL, USA, 2010).

Descriptive statistics as frequency distribution were calculated. Pearson's correlation coefficients were used to evaluate the dependence relationship between variables. The statistical significance level was set to $\mathrm{p}<0.05$.

The breakfast food diary was qualitatively evaluated. From the diary it was possible to identify the various breakfast patterns and those most consumed by the children.

The picture of breakfast was evaluated analyzing a few features suggested by a psychologist aimed at defining the breakfast significance that children ascribed to this meal.

\section{Results}

\section{Sample}

Out of the whole sample, 429 children aged $7.7 \pm 0.4$ years (range 7-8.5) of whom 224 males and 205 females (95.7\% of the pupils involved in the wider nutritional surveillance project), participated in the present study since 19 children were absent because of illness the day in which the survey was carried out.

\section{Questionnaire}

Most of the children (84.3\%) consumed breakfast regularly every day and 7.7\% almost daily. Only $7.3 \%$ of them ( $\mathrm{n}=31$ ) did not consume regularly breakfast while 3 children (0.7\%) skipped breakfast every day. Seventy two point one percent ate this meal with their family and almost the whole sample (94.9\%) considered breakfast a very pleasant occasion. Ninety one pupils had breakfast at home sitting at the table, $3.8 \%$ consumed it in the bed and $3.6 \%$ had breakfast out of home, at a bar (1.9\%) or while going to school (1.7\%) in their parent's car (Table 1).

During breakfast meal, $30.8 \%$ of the pupils ate silently, 32.2\% talked with their family members and $33.1 \%$ watched the television. Sixty two point three percent of the children liked most what they usually ate and drank as well as foods and beverages flavor, while $26.7 \%$ enjoyed most family members' presence.

As far as dental hygiene concerns, $82.9 \%$ of the children brushed their teeth after breakfast consumption and $8.9 \%$ both before and after breakfast eating. Only 3.1\% never brushed their teeth.

In the wider nutrition surveillance study, children's weight and height were measured under standard conditions and BMI was computed [36]. Pupils' BMI who did not consume regularly breakfast or skipped it (8.0\%) showed that 25 of them were normal weight while only 9 were overweight or obese.

\section{Food diary}

From the food diary compiled by the children, we identified the various breakfast patterns and those most consumed by them (Table 2). About quality of meal, $73.3 \%$ percent of the pupils consumed an adequate breakfast with milk or yogurt and cereals products; many of them ate also a fruit or drank a fruit juice.

\begin{tabular}{|l|l|}
\hline Foods and beverages & $\%$ \\
\hline Milk/yogurt + cereals products + (fruit or fruit juice) & 73.3 \\
\hline Tea + cereals products + (fruit or fruit juice) & 12.6 \\
\hline Barley coffee + cereals products + (fruit or fruit juice) & 1.2 \\
\hline Toasted bread with cheese and ham & 2.6 \\
\hline Only a beverage & 5.4 \\
\hline Only cereals products & 4.9 \\
\hline
\end{tabular}

Table 2: Breakfast patterns

Twenty six point seven percent of the children consumed an unsatisfactory breakfast since a few of them (13.8\%) drank tea or barley coffee instead of dairy products, 11 pupils (2.6\%) preferred a breakfast with toasted bread, cheese and ham and $10.3 \%$ ate only one food or drank one beverage.

The results did not show significant differences between males and females $(p=0.21)$ and no significant correlation emerged between breakfast pattern and children's BMI $(\mathrm{p}=0.34)$ showing that pupils' food choices were not affected by their weight status.

\section{Breakfast picture}

In the breakfast pictures made by the children, features needed to draw a child's profile and how they perceived this meal have been analyzed. In the picture, the stroke pencil, the layout in the paper, the size, the color of the picture showed a different way of displaying child's inner life. From this, it was possible to understand in our study the breakfast significance that children ascribed to this meal. 
Pictures qualitative analysis was in line with the previous results showing that most of the children (92.0\%) liked to consume breakfast every day with their family and considered it a very pleasant occasion. Most of the pictures were colored (92.3\%), drawn with light colors by $52.7 \%$ of the children. More than half of the sample (54.8\%) drew in the picture also their family components, $31.2 \%$ described the kitchen environment with specific details while $15.0 \%$ drew only a big cup with milk, biscuits or cakes. In addition, about a quarter of the children (23.6\%) has reported products brands in the picture.

A few breakfast pictures were reported in Figure 2.

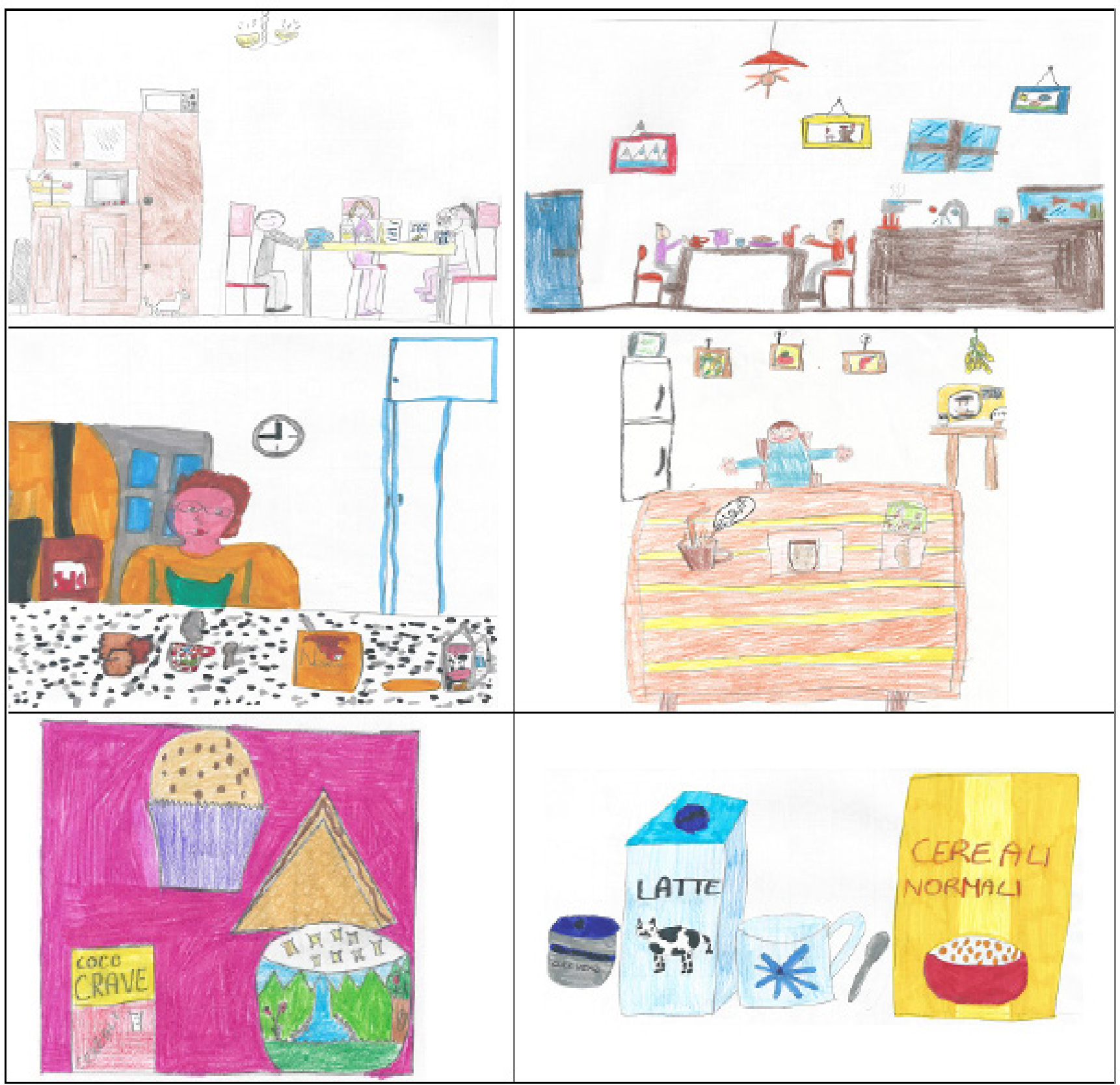

Figure 2: A few breakfast pictures

\section{Discussion}

Breakfast is the most important meal of the day and makes an essential nutritional contribution to overall dietary quality. Indeed, from numerous observational studies it emerged that regular breakfast eaters had higher dietary quality compared to breakfast skippers $[15,31,37-40]$.

The results of our study were encouraging given that $84.3 \%$ of the pupils ate breakfast regularly every day, $7.7 \%$ almost daily while only $8.0 \%$ did not consume it regularly or skipped it. 
Numerous studies in the literature reported that those who consumed breakfast on a daily basis [37-39] showed a nutrient profile high in fiber, calcium, vitamins A and C, riboflavin, zinc, and iron, and low in dietary fat, cholesterol, and energy intake. In contrast, those who skipped breakfast were unable to meet nutritional recommendations from meals consumed throughout the remainder of the day. Overall, these studies documented that regular breakfast consumption was associated with improved diet quality and better food choices throughout the day [37].

Our results were in line with those of the "Okkio alla salute project" [41] involving all Italian regions from which a positive trend emerged: from 2008 during which children skipping breakfast were $11 \%$ to 2012 where percentage of them decreased to $9 \%$. Nevertheless, our data were higher than those reported in a study conducted in Tuscany region [42] on 3076 children aged 8-9 years showing that children skipping breakfast were equal to $3 \%$. On the other hand, our results disagreed with those obtained from a study carried out in the USA [43] reporting that $20 \%$ of American children skipped breakfast as well as those in a study conducted in Santa Fe (New Mexico) [44] in students from two public primary schools in which emerged that only $75 \%$ of children had breakfast on a daily basis.

From the questionnaire it was shown that lack of time as well as lack of appetite together with sleepiness were the principal reasons for not consuming this meal. These observations were in agreement with those emerged from the last survey conducted by the Italian Institute of Statistics [45], as well as those from a study carried out in the USA [46] reporting that commonly held perceptions of barriers to eating breakfast were lack of time and not being hungry in the morning. Also in the study conducted in Santa Fe [44] it was pointed out that lack of time was the main cause for skipping breakfast. It can be suggested that the lack of appetite might be caused by unhealthy dietary habits during the evening meal or by a dinner consumed very late in the night.

Many cross-sectional studies have well documented a relationship between skipping breakfast and higher BMI [5,6,15,17-25], whereas breakfast eating has been shown to be associated with a lower BMI [2,31-33]. Our data were in disagreement with the literature and this could be explained by the fact that overweight and obesity prevalence rate in our sample was small, equal to $15.9 \%$ [36], as well as the percentage of children who skipped breakfast was low, equal to $8 \%$. Indeed, from 34 pupils skipping breakfast only $26.5 \%$ were overweight or obese. On the other hand, our results were in agreement with those found in Tuscany [42] showing that no substantial differences in food choices at the meals analyzed (breakfast, mid-morning and afternoon snack) were determined among normal weight, overweight and obese children, nevertheless those normal weight had a greater tendency to consume meals more regularly.

Since $32.2 \%$ of children liked to talk with their family members and $26.7 \%$ enjoyed most their presence at breakfast, we can argue that this meal represented for our children a very important moment of family sociality. On the other hand, one third of them liked to watch the television and, nevertheless this should be discouraged by switching off it, our result was lower than that obtained in Santa Fe [44] showing more than $50 \%$ of children watching the television while having breakfast.

A previous study conducted in Northern Italy [18] among 1,202 children had shown that, at breakfast time, 48\% pupils consumed their meal in silence, $26 \%$ played with brothers and sisters, $18 \%$ watched television and only $8 \%$ talked with parents.

Results regarding dental hygiene were satisfactory, since most of the pupils brushed their teeth after breakfast consumption, a few both before and after breakfast eating and only a very small percentage (3.1\%) did not brush their teeth. Our data were more encouraging than those reported in Spain [47] showing that of the participants in the study 9.3\% never brushed their teeth.

The breakfast pattern most consumed by the children was balanced and adequate and consisted of milk or yogurt and cereals products; many of the pupils ate also a fruit or drank a fruit juice.

In a number of studies in the literature $[29,31,38,39,43]$, the consumption of breakfast cereal in particular was noted to contribute to an improved nutrient profile. Is has been shown that high-fiber cereals (ie, $>2$ g per serving) and whole-grain products improved satiety and decrease binge eating at lunch or after school [48]. Indeed, promoting a healthful breakfast containing whole grains and fruits, as diets including nutrient- and fiber-rich carbohydrates, has been shown to lead to weight loss and reduce disease risk [37]. In addition, eating cereal at breakfast was indeed associated with an increased consumption of fiber and carbohydrates as well as with a decreased consumption of fats throughout the days, showing that cereals consumption as part of a healthy lifestyle might play a role in maintaining adequate nutrient intake [26]. Moreover, Cho et al. in NHANES III [49] showed that eating cereals (ready-to-eat or cooked cereal) or quick breads for breakfast was associated with significantly lower BMI compared to skipping breakfast or eating meats and/or eggs for breakfast. Lastly, the daily consumption of breakfast based on whole grains cereals and fruit might be protective against the onset of cardiovascular disorders and related mortality [40,50].

On the other hand, our results pointed out that a few children drank tea or barley coffee instead of dairy products and some others consumed an unsatisfactory and inadequate breakfast, given that they only ate one food or drank one beverage.

Breakfast pictures in which children drew their meal specifically detailed, reported the kitchen environment, used numerous colors and often pictured also their family members, confirmed that breakfast represented for them a very pleasant and enjoying occasion as well as a very important moment of family sociality. 
The present study has a few limitations that should be considered. First of all, though our questionnaire was previously piloted on a sample of 52 children and revised accordingly, its validity and reliability were not formally tested. Second, since it is a part of a wider nutritional surveillance project conducted only on children attending the second year of all the public primary schools in Pavia, our results referred to only pupils aged 7-8.5 years and not to the whole children attending the five classes of the primary school.

Despite these limitations, our study also showed some strength. Indeed, breakfast meal has been analyzed from many points of view, such as by a questionnaire, aimed at investigating about the consumption of this meal, and how and with whom it was eaten; by a food diary aimed at outlining the breakfast pattern and by a breakfast picture aimed at understanding how this meal is was perceived by the children.

\section{Conclusion}

In conclusion, our results showed positive and encouraging data regarding the consumption of breakfast by the children in Pavia. Nutritional quality of breakfast was satisfactory, since this meal included dairy products, cereals and in some cases also one fruit or fruit juice and the percentage of children skipping this meal was small. In addition, pupils considered it a very pleasant occasion and enjoyed consuming it with their family members. Children's BMI did not influence breakfast consumption.

Although the results were satisfactory, efforts should be aimed at reinforcing children's positive habits and encouraging these throughout entire life. Parents of pupils skipping breakfast should encourage their children to assume this meal aiming at improving their dietary quality as well as nutrient profile.

\section{Acknowledgements}

The authors would like to express their acknowledgement to the staff of the Education Department of Pavia City Hall: Dr. R. Faldini, Dr. M. Adduci, Dr. P. Mangiarotti, Dr. F. Gallone, Dr. F. Biffi, Dr. L. La Carbonara, Dr.N. Marni. They are very grateful to all the teachers, the pupils and their parents for their continuous cooperation.

The research was supported by grants from Pavia City Hall Education Department.

Each author has participated actively in the work and has given substantial contribution: Giovanna Turconi: project of the study, data analysis and interpretation, writing of the manuscript, supervisor; Stefania Moro: developing of the questionnaire, data collection and interpretation; Lidia Testa: developing of the questionnaire, data collection and interpretation; Miriam Rossi: project of the study, data interpretation; Eleonora Porzio: developing of the questionnaire, data collection and interpretation; Carla Roggi: supervisor; Alessandra Valenti: interpretation of the breakfast pictures; Laura Maccarini: project of the study, data collection, statistical analysis and data interpretation, writing of the manuscript.

\section{Conflict of Interest}

There are no financial or other contractual agreements that might cause conflicts of interest nor any personal financial interest in the work neither any commercial sponsor.

\section{References}

1. Chitra U, Reddy CR (2007) The role of breakfast in nutrient intake of urban schoolchildren. Public Health Nutr 10: 55-8.

2. Pearson N, Biddle SJ, Gorely T (2009) Family correlates of breakfast consumption among children and adolescents. A systematic review. Appetite 52: 1-7.

3. Rampersaud GC, Pereira MA, Girard BL, Adams J, Metzl JD (2005) Breakfast habits, nutritional status, body weight, and academic performance in children and adolescents. J Am Diet Assoc 105: 743-60.

4. Williams P (2007) Breakfast and the diets of Australian children and adolescents: an analysis of data from the 1995 National Nutrition Survey. Int J Food Sci Nutr 58: 201-16.

5. Utter J, Scragg R, Mhurchu CN, Schaaf D (2007) At-home breakfast consumption among New Zealand children: associations with body mass index and related nutrition behaviors. J Am Diet Assoc 107: 570-6.

6. Sjoberg A, Hallberg L, Hoglund D, Hulthén L (2003) Meal pattern, food choice, nutrient intake, and lifestyle factors in The Goteborg Adolescence Study. Eur J Clin Nutr 57: 1569-78.

7. Billon S, Lluch A, Gueguen R, Berthier AM, Siest G, et al. (2002) Family resemblance in breakfast energy intake: the Stanislas Family Study. Eur J Clin Nutr 56: $1011-9$.

8. Lien L (2007) Is breakfast consumption related to mental distress and academic performance in adolescents? Public Health Nutr $10: 422-8$.

9. O’Dea JA, Wagstaff S (2011) Increased breakfast frequency and nutritional quality among schoolchildren after a national breakfast promotion campaign in Australia between 2000 and 2006. Health Educ Res 26: 1086-96.

10. Benton D (2008) The influence of children's diets on their cognition and behavior. Eur J Clin Nutr 47: 25-37.

11. Hoyland A, Dye L, Lawton CL (2009) A systematic review of the effect of breakfast on the cognitive performance of children and adolescents. Nutr Res Rev 22: $220-43$

12. Adolphus K, Lawton CL, Dye L (2013) The effects of breakfast on behavior and academic performance in children and adolescents. Front Hum Neurosci 7: 425.

13. Wesnes KA, Pincock C, Scholey A (2012) Breakfast is associated with enhanced cognitive function in schoolchildren. An internet based study. Appetite 59: 646-9. 
14. Nicklas TA, Reger C, Myers L, O’Neil C (2000) Breakfast consumption with and without vitamin-mineral supplement use favorably impacts daily nutrient intake of ninth-grade students. J Adolesc Health 27: 314-21.

15. Affenito SG, Thompson DR, Barton BA, Franko DL, Daniels SR, et al. (2005) Breakfast consumption by African-American and white adolescent girls correlates positively with calcium and fiber intake and negatively with body mass index. J Am Diet Assoc 105: 938-45.

16. Wilson N, Parnell W, Wohlers M, Shirley P (2006) Eating breakfast and its impact on children's daily diet. Nutr Diet 63: 15-20.

17. Keski-Rahkonen A, Kaprio J, Rissanen A, Virkkunen M, Rose RJ (2003) Breakfast skipping and health-compromising behaviors in adolescents and adults. Eur J Clin Nutr 57: 842-53.

18. Vanelli M, Iovane B, Bernardini A, Chiari G, Errico MK, et al. (2005) Breakfast habits of 1,202 northern Italian children admitted to a summer sport school. Breakfast skipping is associated with overweight and obesity. Acta Biomed 76: 79-85.

19. O’Dea JA, Caputi P (2001) Association between socioeconomic status, weight, age and gender, and the body image and weight control practices of 6- to 19-year old children and adolescents. Health Educ Res 16: 521-32.

20. Andersen LF, Lillegaard IT, Overby N, Lytle L, Klepp KI, et al. (2005) Overweight and obesity among Norwegian schoolchildren: Changes from 1993 to 2000. Scand J Public Health 33: 99-106.

21. So HK, Nelson EA, Li AM, Guldan GS, Yin J, et al. (2011) Breakfast frequency inversely associated with BMI and body fatness in Hong Kong Chinese children aged 9-18 years. Br J Nutr 106: 742-51.

22. Szajewska H, Ruszczynski M (2010) Systematic review demonstrating that breakfast consumption influences body weight outcomes in children and adolescents in Europe. Crit Rev Food Sci Nutr 50: 113-9.

23. de la Hunty A, Gibson S, Ashwell M (2013) Does regular breakfast cereal consumption help children and adolescents stay slimmer? A systematic review and meta-analysis. Obes Facts 6: 70-85.

24. Nurul-Fadhilah A, Teo PS, Huybrechts I, Foo LH (2013) Infrequent breakfast consumption is associated with higher body adiposity and abdominal obesity in Malaysian school-aged adolescents. PLoS One 8: e59297.

25. Toschke AM, Thorsteinsdottir KH, von Kries R; GME Study Group (2009) Meal frequency, breakfast consumption and childhood obesity. Int J Pediatr Obes 4: $242-8$.

26. Albertson AM, Thompson D, Franko DL, Kleinman RE, Barton BA, et al. (2008) Consumption of breakfast cereal is associated with positive health outcomes: evidence from the National Heart, Lung, and Blood Institute Growth and Health Study. Nutr Res 28: 744-52.

27. Baldinger N, Krebs A, Müller R, Aeberli I (2012) Swiss children consuming breakfast regularly have better motor functional skills and are less overweight than breakfast skippers. J Am Coll Nutr 31: 87-93.

28. Coppinger T, Jeanes YM, Hardwick J, Reeves S (2012) Body mass, frequency of eating and breakfast consumption in 9-13-year-olds. J Hum Nutr Diet 25: 43-9.

29. Papoutsou S, Briassoulis G, Hadjigeorgiou C, Savva SC, Solea T, et al. (2014) The combination of daily breakfast consumption and optimal breakfast choices in childhood is an important public health message. Int J Food Sci Nutr 65: 273-9.

30. Tin SP, Ho SY, Mak KH, Wan KL, Lam TH (2011) Breakfast skipping and change in body mass index in young children. Int J Obes (Lond) 35 : 899-906.

31. Barton BA, Eldridge AL, Thompson D, Affenito SG, Striegel-Moore RH, et al. (2005) The relationship of breakfast and cereal consumption to nutrient intake and body mass index: the National Heart, Lung, and Blood Institute Growth and Health Study. J Am Diet Assoc 105: 1383-9.

32. Delva J, Johnston LD, O’Malley PM (2007) The epidemiology of overweight and related lifestyle behaviors. Racial/ethnic and socioeconomic status differences among American youth. Am J Prev Med 33: S178-86.

33. Dubois L, Girard M, Potvin Kent M (2006) Breakfast eating and overweight in a pre-school population: is there a link? Public Health Nutr 9: 436-42.

34. Mikkila V, Rasanen L, Raitakari OT, Pietinen P, Viikari J (2004) Longitudinal changes in diet from childhood into adulthood with respect to risk of cardiovascular diseases: the Cardiovascular Risk in Young Finns Study. Eur J Clinl Nutr 58: 1038-45.

35. Turconi G, Testa L, Moro S, Rossi M, Roggi C, et al. (2013) Acceptability, Waste and Nutritional Adequacy of Primary School Canteen Menus: An Observational Study in Pavia, Northern Italy. J Nutr Food Sci 3: 238.

36. Turconi G, Rossi M, Testa L, Moro S, Roggi C, et al. (2014) Overweight, Obesity and Abdominal Obesity in Primary School Children in Pavia, Northern Italy. J Nutr Health Sci 1: 101.

37. Timlin MT, Pereira MA (2007) Breakfast Frequency and Quality in the Etiology of Adult Obesity and Chronic Diseases. Nutr Rev 65: 268-81.

38. van den Boom A, Serra-Majem L, Ribas L, Ngo J, Pérez-Rodrigo C, et al. (2006) The contribution of ready-to-eat cereals to daily nutrient intake and breakfast quality in a Mediterranean setting. J Am Coll Nutr 25: 135-43.

39. Montenegro-Bethancourt G, Vossenaar M, Kuijper LD, Doak CM, Solomons NW (2009) Ready-to-eat cereals are key sources of selected micronutrients among schoolchildren from public and private elementary schools in Quetzaltenango, Guatemala. Nutr Res 29: 335-42.

40. Giovannini M, Verduci E, Scaglioni S, Salvatici E, Bonza M, et al. (2008) Breakfast: a good habit, not a repetitive custom. J Int Med Res 36: 613-24.

41. OKkio alla salute (2013) Sintesi dei risultati 2012.

42. Lazzeri G, Giallombardo D, Guidoni C, Zani A, Casorelli A, et al. (2006) Nutritional Surveillance in Tuscany: eating habits at breakfast, mid-morning and afternoon snacks among 8-9 y-old children. J Prev Med Hyg 47: 91-9.

43. Deshmukh-Taskar PR, Nicklas TA, O’neil CE, Keast DR, Radcliffe JD, et al. (2010) The Relationship of Breakfast Skipping and Type of Breakfast Consumption with Nutrient Intake and Weight Status in Children and Adolescents: The National Health and Nutrition Examination Survey 1999-2006. J Am Diet Assoc 110: 869-78.

44. Fugas V, Berta E, Walz F, Fortino MA, Martinelli MJ (2013) Breakfast habit and quality in students from two public primary schools in the city of Santa Fe. Arch Argent Pediatr 111: 502-7.

45. ISTAT (2007) Rapporto Annuale - La Situazione del Paese nel 2007.

46. Reddan J, Wahlstrom K, Reicks M (2002) Children's perceived benefits and barriers in relation to eating breakfast in schools with or without universal school breakfast. J Nutr Educ Behav 34: 47-52.

47. Rodríguez Huertas E, Solana Moreno MI, Rodríguez Espinosa F, Rodríguez Moreno MJ, Aguirre Rodríguez JC, et al. (2012) CASERIA program (Healthy Habits in Primary School Questionnaire). Responses of 6 to 10 year-old children. Semergen 38: 265-77. 
48. Jackson LW (2013) The most important meal of the day: why children skip breakfast and what can be done about it. Pediatr Ann 42 : $184-7$.

49. Cho S, Dietrich M, Brown CJ, Clark CA, Block G (2003) The effect of breakfast type on total daily energy intake and body mass index: results from the Third National Health and Nutrition Examination Survey (NHANES III). J Am Coll Nutr 22: 296-302.

50. Liu S, Sesso HD, Manson JE, Willett WC, Buring JE (2003) Is intake of breakfast cereals related to total and cause specific mortality in men? Am J Clin Nutr 77: 594-9. 